\title{
Conservative Management of Discolored Maxillary Central Incisor with Open Apex Using Mineral Trioxide Aggregate (MTA) Apical plug and walking bleach Method: A case report.
}

\begin{abstract}
Esthetics enhancement is a better treatment option for a non-fracture discolored traumatic maxillary central incisor ( $\mathrm{Max} \mathrm{Cl}$ ). The traumatic injury occurred in $\mathrm{Max} \mathrm{Cl}$ teeth because it was present in the most anterior region of the jaw. Necrosis (pulpal) in $\mathrm{Max} \mathrm{Cl}$ is the second commonest complication after fracture due to trauma. Open apex, incomplete root development, root shortening, roots with a poor remaining dentinal thickness (RDT), and a compromised crown root ratio all these factors affect the survival prognosis of traumatized teeth. Nowadays MTA based bio regenerative material helps in treatment strategies like apexification that was a popular treatment of open apex cases. Necrosis associated discoloration is managed with a conservative approach non-vital bleaching, less time consuming, and satisfy the economical and esthetic aspect for the patient.
\end{abstract}

Keywords: OpenApex, MTA, Non-vital bleaching, Custom Made Gutta Purcha.

\section{Introduction:}

The endodontic management for the open apex, necrosis of pulp with discoloration is to obtain three-dimensional apical end closures from the access point to root end of a tooth for better long term outcome.[1] 92\% traumatic accident responsible for pulpal damage, with associated factors abnormal growth, short roots and fracture in max CI.[2] Blunderbuss open apexes commonly divided in nonblunderbuss and blunderbuss type which characterized parallel walls or less convergent and cylindrical apex or less tapered ie. Non-blunderbuss but in blunderbuss all futures are opposite like divergent, flaring. [3]

In open apex cases, apical plug (apical barrier) or apexification is the only treatment option. A technique that inducing a calcified apical barrier at root end for open apex or the continued apical development of an incompletely formed root in teeth with necrotic pulp called apexification. Calcium hydroxide widely used intracanal medicament for apexification but recently substituted with MTA

\begin{tabular}{|l|c|}
\hline \multicolumn{2}{|c|}{ Access this article online } \\
\hline \multirow{2}{*}{$\begin{array}{l}\text { Website: } \\
\text { www.ujds.in }\end{array}$} & Quick Response Code \\
\hline $\begin{array}{l}\text { DOI: } \\
\text { https://doi.org/10.21276/ujds.2020.6.3.22 }\end{array}$ \\
\hline
\end{tabular}

biocompatible material to induce apexification in a young permanent tooth because of calcium hydroxide interfere with dentine internal structure which is the cause of root fracture. [4-6]

In past years, various techniques introduce for discolored tooth management but walking bleach method widely accepted which was based on the chemical reaction of a

\footnotetext{
${ }^{1}$ PATHAK V. K., ${ }^{2}$ SAXENA T., ${ }^{3}$ SINGH K., ${ }^{4}$ JAIN K. 1,3,4 Department Of Conservative Dentistry \& Endodontics, Maharana Pratap College of Dentistry \& Research Centre, Gwalior.

${ }^{2}$ Department Of Conservative Dentistry \& Endodontics, Seema Dental College and Hospital, Rishikesh.
}

Address for Corresponding : Dr. Vivek Kumar Pathak MDS, Senior Lecturer, Department Of Conservative Dentistry \& Endodontics, Maharana Pratap College of Dentistry \& Research Centre, Gwalior. Mail id- vivekpathak786@gmail.com

Received : 20 August 2020, Published : 31 Dec. 2020 
combination of sodium tetra perborate and water or $35 \%$ hydrogen peroxide. The excellent esthetic walking bleach result depends on chemical agent reaction with chromophore molecules which are responsible for tooth discoloration. [7]

The recent conservative era has allowed clinicians to simulate the original dental anatomy, thus rehabilitating function and esthetics in a short time by preserving dental tissues with the help of different new restorative material. This case represents conservative management of discolored Max CI with open apex using MTA based apical plug technique followed by walking bleach technique.

\section{Case Report}

A 21-Year-old patient arrived in the Department of Conservative Dentistry \& Endodontic, with the chief complaint of discolored maxillary right central incisor with a fall history in the previous year. In the past dental history, she has visited a private clinic a few days ago but not satisfied with the treatment plan. Past medical history was not relevant. In clinical examination discoloration of tooth \#[11] without mobility, no tender on percussion, no response in cold and hot, and radiographic examination show open apex, periapical radiolucency. The final diagnosis was pulpal necrosis with chronic apical periodontitis with tooth \#[11]. After discussing we suggest MTA apical plug or apexification single-step. The consent form was obtained from the patient in writing. Root canal treatment was started under rubber dam isolation with a foldable frame and access opening (\# 11) using access opening burs. Working length was measured as $20.5 \mathrm{~mm}$ with 80 size K-file (Sybron Endo, Korea) using an apex locator (Aped ID, Sybron Endo, Korea) with an electronic apex locator (Apex ID) and confirmed with a radiograph. Cleaning and shaping were done with the circumferential filing technique. Irrigants was Using 3\% sodium hypochlorite (Parcan, Septodont health LTD), followed by $17 \%$ Ethylenediaminetetraacetic acid (EDTA) (Metabio) with endo closed side vented needle. Final irrigation was done with 2\% chlorhexidine (Parcan, Septodont health LTD). Sterilized Paper points were used for drying the canal. White MTA Angelus (Angelus, Londrina, PR, Brazil) was prepared according to instructions and condensed with less apical pressure using hand plunger instruments to form apical plug about 3-4 $\mathrm{mm}$. After that a moist paper point with cotton placed in the canal over MTA, and closed with Temp Paste (Pyrex Exports, India). After 24 hours, obturation was completed with custom made gutta purcha cone technique (Meta Biomed, Korea) and Seal Apex sealer (Sybron Endo, Korea) by warm vertical condensation and partial post obturation with GC Type IX cervically $2 \mathrm{~mm}$ for walking bleach method. Two walking bleach performed with sodium perborate and $35 \%$ hydrogen peroxide combination for 1 weak in Intra coronal space closed with Temp Paste (Pyrex Exports, India). Then the final post obturation was done with composite resin restorative (Ivoclar). Oral examination revealed Post proper 24-hour follow-up is mandatory. At the follow-up visit, the case showed a satisfactory outcome after a one-month recall visit verified by radiographic examination.(Figure 1, Figure2)

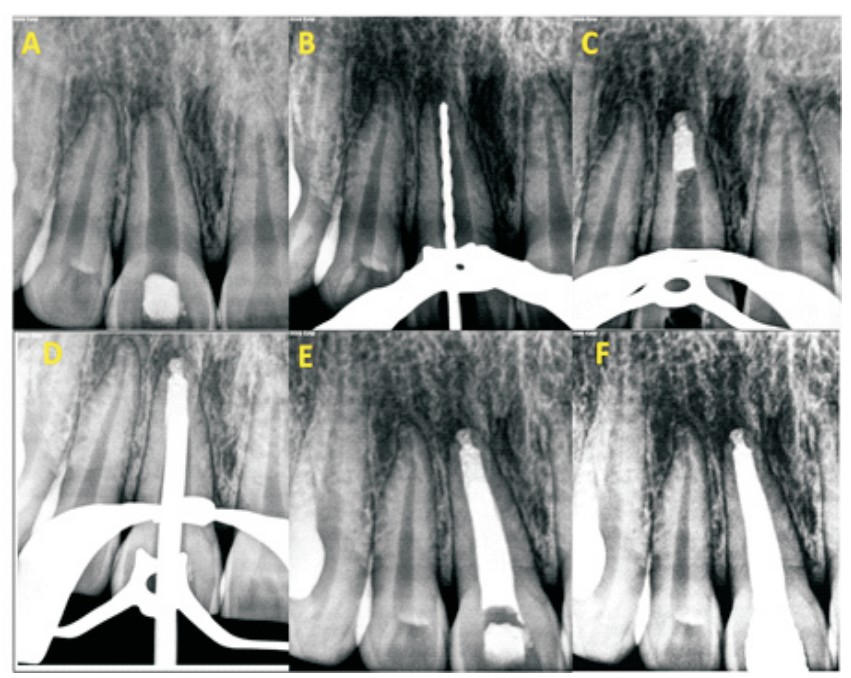

Figure 1. IOPAR of Endodontic Procedures- A) Pre Operative B)Working Length, C) Apical Plug, D) Master Cone, E) Obturation F) Post Obturation
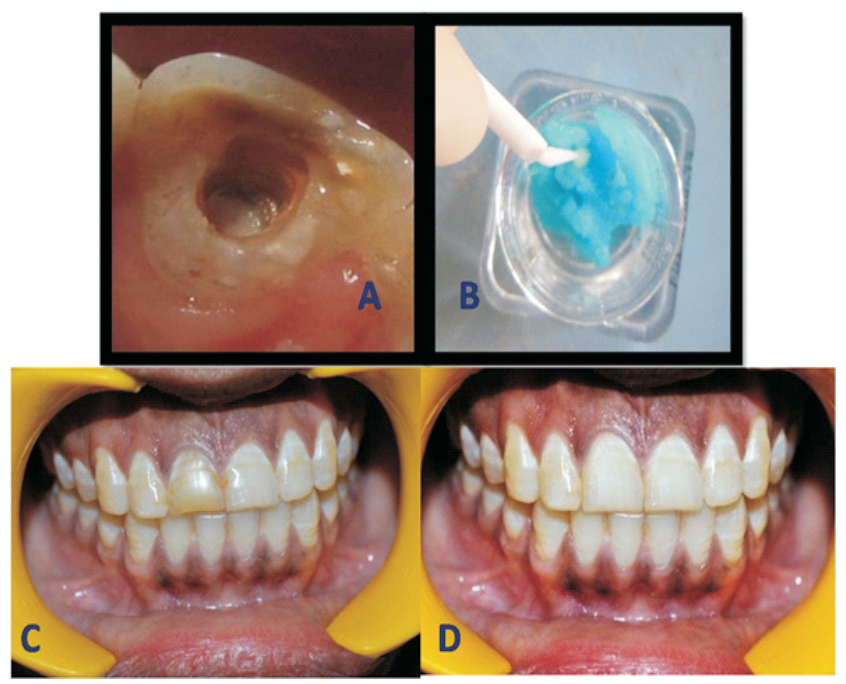

Figure 2. A) Pulp Chamber Space Photograph, B) Mixture of Walking Bleach, C)Pre Clinical Photograph, D) Post Clinical Photograph 


\section{Discussion:}

The non-surgical approach is the most conservative treatment of choice for necrotic pulp and open apex with biocompatible material in contemporary dentistry.8 In the past, calcium hydroxide intracanal medicament was used to form apical barrier and control infection, but it will take 3-4 months and multiple dental office visits that were inconvenient for patients and clinicians. Nowadays single visit apexification has more convenient with fewer chances of reinfection, less dental office visits, and time saving.[6]

MTA introduce by Torabinejad et al. with various advantages like highly biocompatible, compatible with blood, induce bone formation, better sealing property with antibacterial effect on various bacterial species.[4] Calcium hydroxide is now substituted with MTA used for an artificial root end plug this treatment strategy was widely accepted by the dentist that helps in immediate endodontic procedures like obturation because its less time consuming but with disadvantages like long setting time, higher cost. [1, 3, 9-10] Various case reports and series concluded that use of MTA Angelus, ProRoot MTA, tooth-colored ProRoot MTA, Biodentine, Bio Aggregate, and CEM cement has better treatment outcome in open apices cases as apical plug filling material and not any cases have shown pain, reinfection, or radiographic enlargement of preexisting apical pathology.[11-12]

Accidental traumatic non-esthetic pigmented max CI teeth esthetic correction that can also manageable with invasive full veneers, laminates, crowns, or noninvasive techniques such as walking bleach. Walking bleach comes under nonvital bleaching is a minimally invasive technique, more economical, long term color stability, and requires less chair time therefore more popular. Long-chain organic molecules are responsible for the intrinsic pigmentation of the pulp chamber. Sodium Perborate and hydrogen peroxide-based bleach technique which oxidizes these long-chain molecules (convert carbon while liberating water and oxygen) is used in paste consistency in the pulpal space. $[7,13]$

Recent advancements like Choukroun's technique are PRF (Platelet-rich fibrin a strong fibrin membrane enriched with platelet and growth factors) a new therapeutic concept for open apex cases.[14] Sharma et al. conducted a case series and concluded that a combination of PRF (Platelet-rich fibrin) as a matrix and MTA as an apical plug or artificial apical barrier.[15] Now we can calibrate the diameter of open apex in cubic millimeter by CBCT (cone beam computed tomography), Spiral CT (computed tomography), and Ultrasound also confirmed the nature of the periapical tissues. [16]

\section{Conclusion:}

Novel bio regenerative and highly biocompatible material like MTA (calcium silicate) based single-visit apexification can be a better option for open apex cases to achieve a higher success rate in today's scenario. This case report suggested that MTA based one visit apexification with walking bleach is the best conservative procedure of choice which restores the esthetic of the natural tooth for the patient. Patient's awareness about treatment limitation and cooperation is important for a good prognosis. The good clinical skills need to achieve an esthetic goal to restore natural tooth structure with minimal intervention dentistry.

\section{References:}

1. Guerrero F, Mendoza A, Ribas D, Aspiazu K. Apexification: A systematic review. J Conserv Dent 2018;21:462-5

2. Andreasen JO, Andreasen FM, Andersson L. Textbook and Color Atlas of Traumatic Injuries to the Teeth. Oxford, UK: Blackwell; 2007.

3. Patil N, Jain A, Hegde D, Patil A. Management of teeth with blunderbuss canals and its esthetic rehabilitation. Int J Med Dent Case Rep 2020;6:1-5.

4. Torabinejad M, Chivian N. Clinical applications of mineral trioxide aggregate. J Endod 1999;25:197-205.

5. Das T, Gupta S, Atom J, Lairenlakpam R, Gupta S, Chaudhary A. Endodontic management of blunderbuss canal with open apex and Ellis Class IV fracture using mineral trioxide aggregate andcompo-post. Int J Prev Clin Dent Res 2019;6:66-8.

6. Pace R, Giuliani V, Pini Prato L, Baccetti T et al. Apical Plug technique using mineral trioxide aggregate: results from a case Series. Int Endod J 2007;40:478-48.

7. Attin T, Paque F, Ajam F, Lennon AM. Review of the current status of tooth whitening with the walking bleach technique. Int Endod J. 2003;36:313-29.

8. Kumar SM, Kumar T, Keshav V, Arora S, Singla A. Open apex solutions: One-step apexification, salvaging necrosed teeth with open apex. Endodontology 2019;31:173-8.

9. Li C, Zheng Z, Deng X, Zhang L, et al Apexification Management of Mandibular Second Premolar with a Blunderbuss Apex and Periapical Lesion of an Adult Patient. Case Rep Dent 2019;2019:1-4. 
10. Purra AR, Ahangar FA, Chadgal S, Farooq R. Mineral trioxide aggregate apexification: A novel approach. J Conserv Dent 2016;19:377-80.

11. Shah N, Logani A, Bhaskar U, Aggarwal V. Efficacy of Revascularization to Induce Apexification/Apexogensis in Infected, Nonvital, Immature Teeth: A Pilot Clinical Study. J. Endod 2008;34(8):919-925.

12. Mineral trioxide aggregate and other bioactive endodontic cements: an updated overview - part II: other clinical applications and complications. Int Endod J. 2018;51:284-317.

13. Almohareb T. Management of discolored endodontically treated tooth using sodium perborate. J Int Oral Health.2017;9:133-5.

14. Jain JK, Ajagannanavar SL, Jayasheel A, Bali PK, Jain CJ. Management of a fractured nonvital tooth with open apex using mineral trioxide aggregate as an apical plug. Int J Oral Health Sci 2017;7:44-7.

15. Sharma V, Sharma S, Dudeja P, Grover S. Endodontic management of nonvital permanent teeth having immature roots with one step apexification, using mineral trioxide aggregate apical plug and autogenous platelet-rich fibrin membrane as an internal matrix: Case series. Contemp Clin Dent 2016;7:67-70.

16. Reddy S, Sukumaran VG, Bharadwaj N. Tailor-made endodontic obturatonmanagement of Blunderbuss canal. J Conserv Dent 2011;14:199-202. 